\title{
Diagnóstico da gestão da qualidade na produção familiar de hortaliças do município de São Carlos-SP
}

\author{
Luciano Silva Lima (UFSCar) luciano@dep.ufscar.br \\ José Carlos de Toledo (UFSCar) toledo@power.ufscar.br
}

\begin{abstract}
Resumo
O presente trabalho está inserido em um projeto de pesquisa mais amplo que objetiva desenvolver um modelo de gestão integrada para a agricultura familiar. $O$ trabalho apresenta os resultados de uma pesquisa de campo, realizada junto a produtores familiares de hortaliças, que teve por objetivo identificar e analisar a percepção da importância e a adoção de conceitos e práticas básicas de gestão da qualidade, por esses produtores. A pesquisa de campo foi conduzida junto a uma amostra de 33 produtores familiares de hortaliças do Município de São Carlos, por meio de entrevistas conduzidas na propriedade utilizando-se de um questionário. Para o levantamento de dados foram consideradas práticas relativas ao planejamento, ao controle e à melhoria da qualidade. De modo geral observa-se que praticamente a totalidade desses produtores, mesmo percebendo a importância da adoção de determinados conceitos e práticas, não as concretiza na gestão de sua propriedade por razões que recaem, sobretudo, na ausência de uma estrutura gerencial.

Palavras chave: Gestão da Qualidade, Agricultura Familiar, Horticultura.
\end{abstract}

\section{Introdução}

Um grupo de pesquisadores do Departamento de Engenharia de Produção da Universidade Federal de São Carlos está desenvolvendo um sistema de gestão integrada da agricultura familiar, fomentado pelo Conselho Nacional de Desenvolvimento Científico e Tecnológico. Tal sistema é formado pelos seguintes módulos: Planejamento da Produção, Sistemas de Custeio e Indicadores de Desempenho, Gestão da Qualidade, Comercialização, Marketing e Recursos Financeiros.

Especificamente em relação ao módulo de Gestão da Qualidade, o projeto visa conceber um sistema prático que permita ao produtor familiar implantar de uma forma simples a gestão da qualidade em seu empreendimento, no sentido de garantir a qualidade dos produtos e melhorar continuamente seus processos produtivos e gerenciais, contribuindo para a redução de perdas e custos, bem como para a oferta de alimentos seguros e com a qualidade assegurada aos consumidores. Ademais, vislumbra-se uma eventual certificação da qualidade, melhorando as condições de comercialização de seus produtos.

O presente artigo tem por objetivo principal apresentar um diagnóstico, sob a ótica da Gestão da Qualidade, realizado em uma amostra de estabelecimentos rurais produtores de hortaliças pertencentes à agricultura familiar. $\mathrm{O}$ diagnóstico foi desenvolvido a partir de uma pesquisa de campo de cunho qualitativo, conduzida junto a 33 propriedades familiares de hortaliças do município de São Carlos-SP, através de visitas seguidas de entrevistas mediante aplicação de um questionário. Os dados coletados referem-se ao período de outubro de 2001 a setembro de 2002.

Segundo o Censo Agropecuário de 1996 (IBGE, 2003), o município de São Carlos-SP possui um total de 200 estabelecimentos familiares, ocupando uma área de 6.560 ha e respondendo 
por um valor bruto da produção $(\mathrm{VBP})$ de $\mathrm{R} \$ 7.152 .000,00$. Em relação à produção de hortaliças, o município conta com 48 estabelecimentos familiares, numa área de 1.180 ha e VBP de R\$ 383.000, ficando atrás apenas da produção de frango, cana, leite e milho.

\section{A Agricultura familiar no Brasil}

Definir o que é agricultura familiar não é uma tarefa trivial. Guanziroli et al. (2001) partem de um conceito mais geral no qual são considerados estabelecimentos agrícolas de caráter familiar, aqueles que atendam, ao mesmo tempo, tanto a condição de que a direção dos trabalhos da propriedade rural seja exercida pelos produtores, como a condição de que a quantidade de mão-de-obra familiar seja superior à contratada. Do ponto de vista conceitual, os autores destacam ainda que não se define agricultura familiar a partir do porte do estabelecimento, cuja extensão máxima é determinada pelo que a família pode explorar com base no seu próprio trabalho associado à tecnologia de que pode dispor.

A importância da agricultura familiar no Brasil pode ser evidenciada nos dados do Censo Agropecuário de 1996, o qual identificou um total de 4,1 milhões de estabelecimentos agropecuários familiares, correspondentes a $85,1 \%$ do total de estabelecimentos existentes, ocupando $30,5 \%$ da área total e respondendo por $38 \%$ do valor bruto da produção (VBP) agropecuária do país. Agricultores em melhores condições econômicas, que obtêm rendas superiores ao custo de oportunidade da mão-de-obra familiar são responsáveis por $30,3 \%$ do VBP agropecuária do país. Agricultores em piores condições, que recebem renda abaixo do custo de oportunidade, são responsáveis por apenas 7,7\% do VBP da agropecuária nacional, mas representam $56,3 \%$ do número total de estabelecimentos rurais.

Tais dados demonstram a importância social e econômica da agricultura familiar no Brasil, uma atividade que, mesmo diante de tantas pontencialidades, possui muitas fragilidades: se por um lado a agricultura familiar se destaca por sua capacidade em termos da produção agrícola, por outro ela ainda é constituída por um grande contingente vivendo em condições sociais e de produção extremamente heterogêneas, muitas vezes até envolvendo bolsões de pobreza rural. Vale dizer que a viabilidade da agricultura familiar depende não somente de condicionantes externos - como, por exemplo, as políticas de crédito e de assistência técnica , mas também de sua capacidade de gestão, a qual, muitas vezes, é comprometida pela complexidade e particularidades inerentes à própria agricultura familiar.

\section{Horticultura e qualidade}

Hortaliças são plantas indispensáveis na dieta alimentar por fornecerem ao organismo humano, vitaminas, sais minerais e fibras. No Brasil, há mais de 80 espécies cultivadas comercialmente, porém, sabe-se que a oferta de hortaliças não é constante, resultando em preços e qualidade diferenciados ao longo do ano. Entre os produtos vendidos no setor de perecíveis dos supermercados, elas estão entre as campeãs de perdas, que, sejam em qualidade, sejam em quantidade, geram prejuízos ao varejo e insatisfação ao consumidor (LANA et al., 1998).

Segundo Gomes (1996), a má conservação de um produto provoca perdas quantitativas (perda de peso ou derrame, caixas quebradas, sacos furados etc), qualitativas (perda do valor nutricional, alteração no sabor, contaminação microbiana) ou econômicas (perda do valor comercial). Tais perdas de hortaliças são devidas, em parte, a fatores decorrentes de danos fisiológicos causados por alterações no funcionamento normal das reações necessárias à vida da planta, de danos mecânicos causados por manuseio inadequado (amassamento, rachaduras) e de danos biológicos causados por ataques de fungos e bactérias (causadores de doenças) e por ataques de insetos (alimentos "bichados"). Para garantir a conservação de sua qualidade, as hortaliças demandam um manuseio especial. Tal como todo produto agrícola perecível, as 
hortaliças devem ser manuseadas o mínimo possível para que sua qualidade seja preservada. No entanto, é preciso salientar que as operações de pós-colheita restringem-se apenas a manter a qualidade inicial do produto pelo maior período de tempo possível, valendo ressaltar que a qualidade e o estado geral do produto não podem ser melhorados após sua colheita.

Numa horta convencional, as principais atividades realizadas pelo produtor, segundo Makishima (1993), são: escolha do local, análise da água, análise e preparo do solo, adubação, produção e transplante de mudas, irrigações/regas, capinas, raleação, desbaste, desbrota, estaqueamento, amontoa, controle de pragas e doenças, colheita e operações de pós-colheita (manuseio, armazenagem e transporte). Tais atividades não estão aqui detalhadas por não serem focos de estudo desse trabalho, valendo destacar que para cada atividade do processo produtivo há recomendações técnicas específicas voltadas, sobretudo, para ganhos em produtividade e em qualidade dos produtos, e que são difundidas em publicações científicas especializadas.

Em suma, a conservação das hortaliças começa no campo, com práticas culturais adequadas e continua até o consumo para que apresentem boa aparência durante a comercialização. E, no que compete ao produtor, é essencial que este garanta que as hortaliças produzidas em sua horta cheguem aos pontos de venda com a qualidade garantida, com o mínimo de perdas possível. Para tanto, é fundamental que ele adote sistematicamente - desde o preparo do solo, passando pelo cultivo e colheita, até a entrega ao cliente ou consumidor final - as práticas recomendadas capazes de conservar a qualidade dos produtos por mais tempo, de modo que os clientes venham a adquirir produtos com um nível de qualidade esperado e adequado aos fins a que se destinam.

\section{Gestão da qualidade}

Considera-se um alimento de qualidade aquele capaz de suprir as necessidades do cliente, tanto ao nível de conveniência como ao nível de suas propriedades fundamentais (organolépticas, nutritivas, funcionais, de higiene e de segurança), além de mantê-lo informado quanto aos cuidados durante o seu manuseio (modo de conservação, preparo e ingestão), e estar em conformidade com a respectiva legislação vigente. Especificamente em relação ao setor agroalimentar, espera-se que a gestão da qualidade contemple os requisitos de segurança do alimento, atendendo às características intrínsecas do produto e os requisitos associados à satisfação do consumidor, com base nas exigências legais (TOLEDO, 1997).

De modo geral, a gestão da qualidade na prática pode ser estabelecida por um conjunto de dimensões e atividades que devem ser desenvolvidas e aplicadas sistematicamente na organização, visando sempre à garantia da qualidade dos produtos e à melhoria dos processos. Assim sendo, uma maneira de analisar a gestão da qualidade numa empresa é identificar a "percepção" que as pessoas envolvidas nos processos (produtivos e gerenciais) possuem da importância dessas dimensões e atividades da gestão da qualidade e também, verificar a "presença" ou "aplicação" dessas dimensões no dia-a-dia da empresa.

No caso específico do diagnóstico realizado, empregou-se essa linha de raciocínio: a partir do que a teoria prevê como dimensões básicas que uma empresa deve adotar para realizar sua gestão da qualidade, tentou-se - a partir das respostas coletadas junto aos produtores familiares de hortaliças de São Carlos-SP - verificar a presença dessas dimensões e atividades nos estabelecimentos rurais, mediante a evidência ou não da adoção de práticas relacionadas a isso no dia-a-dia da atividade. Na medida do possível, tentou-se observar também a percepção que esses produtores possuem da importância de tais dimensões e atividades, fato que muitas vezes pode justificar a adoção ou não de determinadas práticas. 
Para tanto, cabe explicitar quais são essas dimensões e atividades da gestão da qualidade" adotadas aqui como referência. A gestão da qualidade, de acordo com Slack (1999), constitui uma das áreas associadas às estratégias infra-estruturais das operações produtivas das empresas - aquelas que influenciam diretamente as atividades de planejamento, controle e melhoria - sendo definida, conforme Toledo (1997), como "a abordagem adotada e o conjunto de práticas utilizadas para obter, de forma eficiente e eficaz, a qualidade pretendida para o produto".

Seguindo essas definições, pode-se estruturar a gestão da qualidade em três dimensões, sendo elas: Planejamento da Qualidade, Controle da Qualidade e Melhoria da Qualidade.

Planejar a Qualidade consiste em levantar todos os requisitos demandados para o produto ou gama de produtos que a empresa produz (tudo aquilo que é exigido, seja pelos clientes, consumidores, pela legislação, por instituições de classe ou mesmo pela própria empresa), considerando-se a capacidade que a empresa tem de atendê-los em termos de recursos necessários (instalações, equipamentos, instrumentos e materiais de trabalho, pessoas, recursos naturais, recursos financeiros etc.), para então definir objetivos e planejar os processos e tarefas no sentido de contribuir para que tais requisitos sejam atendidos no produto final e ao menor custo possível. Nessa dimensão, três atividades são destacadas, sendo: 1- Identificação das necessidades dos clientes, 2- Identificação de outros requisitos (legais, institucionais, de mercado e mesmo requisitos próprios da empresa) e 3-Definição de objetivos da qualidade (definição exata daquilo que se pretende para insumos, produtos e processos), resultando num plano de atividades capaz de descrever "como" atingir tais objetivos (definição de todas as tarefas demandadas, sua seqüência lógica, suas inter-relações, os recursos necessários, responsabilidades, prazos e como devem ser realizadas).

Controlar a qualidade significa basicamente, através de meios adequados, buscar a garantia da qualidade tanto dos insumos adquiridos, como do processo produtivo e também do próprio produto acabado, não se restringindo apenas à inspeção do produto final como tradicionalmente se costuma fazer. Em relação aos insumos necessários à produção, é preciso que a empresa esteja segura em adquirir insumos que tenham as características ideais para o fim proposto, isto é, com a qualidade esperada. Quanto ao processo produtivo, é importante que a empresa seja capaz de visualizar a seqüência de todas as atividades essenciais e a melhor maneira de realizá-las para a obtenção da qualidade do produto final, verificando se cada etapa está sendo realizada conforme o esperado, ou seja, assegurando que o resultado de uma etapa específica esteja dentro da expectativa estabelecida para a etapa seguinte do processo. Em termos de produto acabado ou produto final, é fundamental garantir que o mesmo esteja em conformidade com as especificações estabelecidas previamente, a partir dos requisitos da qualidade definidos no planejamento. Ademais, deve-se garantir a qualidade do produto final mesmo após a produção propriamente dita, ou seja, é preciso assegurar que a qualidade desse produto seja preservada, mediante a realização adequada das atividades de manuseio, armazenagem e transporte do produto até o cliente. Em suma, a dimensão Controle da Qualidade pode ser representada basicamente por atividades voltadas para a garantia da qualidade em termos de: 1- Insumos, 2- Processo, 3- Produto Acabado e 4- Preservação da Qualidade.

Para Melhorar a qualidade exige-se da empresa a postura de estar voltada ao aprimoramento contínuo de seus processos, tanto produtivos quanto gerenciais. É procurar estar constantemente identificando problemas (reais ou potenciais) e gerando, implementando e padronizando ações consistentes que resultem em soluções efetivas, de modo a evitar a repetição de problemas já ocorridos e também prevenir que outros eventuais venham a ocorrer pela primeira vez. Para tanto, é fundamental monitorar o desempenho da organização através do estabelecimento de indicadores capazes de revelar um bom ou mau desempenho de suas 
atividades (incluindo o da própria gestão da qualidade) -, bem como avaliar a satisfação dos clientes para obter informações de como seus produtos estão sendo percebidos por eles. Assim, a dimensão Melhoria da Qualidade é constituída pelas seguintes atividades: 1Avaliação da Satisfação dos Clientes, 2- Avaliação de Desempenho, 3- Identificação de Problemas e 4- Ações de Melhoria.

Tais dimensões e atividades da gestão da qualidade podem ser visualizadas no Quadro 1.

Quadro 1 - Dimensões e Atividades de Gestão da Qualidade.

\section{Resultados e discussão}

Os principais resultados obtidos na pesquisa de campo foram os seguintes:

\begin{tabular}{|c|c|c|c|}
\hline \multicolumn{4}{|c|}{ GESTÃO DA QUALIDADE } \\
\hline DIMENSÕES & Planejamento da Qualidade & Controle da Qualidade & Melhoria da Qualidade \\
\hline$\underline{\text { ATIVIDADES }}$ & $\begin{array}{l}\text { - Identificação das necessidades } \\
\text { dos clientes; } \\
\text { - Identificação de outros } \\
\text { requisitos; } \\
\text { - Definição de objetivos da } \\
\text { qualidade. }\end{array}$ & $\begin{array}{l}\text { - Insumos } \\
\text { - Processo } \\
\text { - Produto Acabado } \\
\text { - Preservação da Qualidade. }\end{array}$ & $\begin{array}{l}\text { - Avaliação da Satisfação dos } \\
\text { Clientes } \\
\text { - Avaliação de Desempenho } \\
\text { - Identificação de Problemas } \\
\text { - Ações de Melhoria }\end{array}$ \\
\hline
\end{tabular}

Pouco mais da metade dos produtores (52\%) afirmou não buscar informações sobre as necessidades dos clientes. Em relação às exigências legais, a mesma quantidade de produtores afirmou não possuir nenhum tipo de conhecimento, sendo que $48 \%$ demonstraram ter conhecimento superficial sobre alguns pontos específicos, destacando-se: as exigências em termos de uso de agrotóxicos, a nova lei de embalagens, descarte de lixo e reflorestamento.

Para 64\% dos entrevistados, o fornecedor de insumos constitui a principal fonte de informações técnicas para produção (quais as sementes de melhor qualidade, melhor adubo, quantidade adequada para aplicação etc.), o que se justifica pelo fato do principal fornecedor disponibilizar o serviço de um agrônomo, que passa as recomendações que os produtores precisam no dia-a-dia. Em relação à decisão de "como" produzir, 48\% dos produtores disseram basear-se unicamente na experiência pessoal, na tradição da família, enquanto que $42 \%$ assumiram que, além de produzirem com base na tradição, procuram se atualizar, complementando com informações de outras fontes (mídia, instituições de pesquisa e observando a experiência de seus vizinhos). Devido ao forte sentimento de confiança que possuem junto ao fornecedor, 70\% dos produtores afirmam não realizar nenhum tipo de inspeção nos insumos que adquirem e quase a totalidade dos entrevistados (85\%) disseram nunca ter qualquer tipo de problema com seus fornecedores.

Apesar da dificuldade técnica de conseguir uma padronização dos produtos hortícolas, $82 \%$ dos produtores demonstraram perceber a importância disso, sendo que, dessa parcela, 78\% disseram fazer algo na prática. Por outro lado, questiona-se até que ponto os produtores dão a devida importância a isso, pois apenas $36 \%$ revelaram que buscam informações sobre os padrões de qualidade dos produtos e somente $15 \%$ disseram realmente sentir necessidade de uma tabela que defina padrões de qualidade para seus produtos no mercado.

Sabe-se que um dos fatores que contribui para manter um mesmo padrão de produtos é justamente garantir que todo o pessoal envolvido na atividade realize suas tarefas de uma mesma maneira, conforme as técnicas recomendadas. Nesse sentido, $85 \%$ dos produtores 
afirmaram que todas as pessoas em sua propriedade aplicam as técnicas do mesmo modo, mostrando perceberem a importância disso. Todavia, metade desses não conseguiu dizer como garantir na prática. O treinamento foi um dos meios mais citados pelos que dizem garantir isso.

Em relação a essa questão, apenas um produtor disse já ter recebido treinamento formal (realização de um curso fora da propriedade). Os demais afirmaram que nunca tiveram acesso a treinamento desse tipo. Porém, 33\% disseram realizar algum tipo de treinamento interno, o qual foi justificado principalmente quando da contratação de um novo funcionário. Pelo que foi observado, associam treinamento com qualquer atividade de busca e transferência de conhecimento sobre as técnicas de produção. Conhecimento esse normalmente obtido externamente junto a livros, programas rurais na televisão, produtores vizinhos, informativos de instituições de pesquisa etc. e transferido aos demais membros da propriedade durante a própria realização dos trabalhos no dia-a-dia. Aqueles produtores que afirmaram não haver nenhum tipo de treinamento justificam dizendo que a experiência que possuem já seria suficiente.

Um ponto polêmico por estar diretamente ligado à segurança do alimento é a questão da aplicação de agrotóxicos: quase $80 \%$ dos produtores afirmam que aplicam algum tipo de agrotóxico seja para prevenir, para controlar ou para sanar as plantas de pragas e doenças. Apenas 15\% afirmaram não utilizar nenhum tipo de agrotóxico na horta. Quando questionados sobre quanto tempo esperam para colher as hortaliças após aplicação do agrotóxico, $42 \%$ citaram a obediência ao período de carência recomendado no rótulo do produto. Vale dizer que $12 \%$ do total de produtores confirmaram que não obedecem ao período estipulado, seja por motivo da pressão em terem que colher para não deixarem faltar no mercado, seja pelo fato de saberem que outros produtores também não o fazem e nem por isso deixam de vender. Os demais produtores simplesmente estimaram um período em dias, afirmando ser o que normalmente seguem.

Em relação à qualidade da água utilizada na horta, $73 \%$ dos produtores afirmaram que não exercem nenhum tipo de controle e, mesmo dentre aqueles que já fizeram a análise da água, há quem afirme desconhecer o resultado dos testes. Em relação à análise de solo da propriedade, $27 \%$ disseram nunca ter feito e $24 \%$ afirmaram fazê-la com certa freqüência, sendo que os demais já fizeram pelo menos uma vez, mas há mais de dois anos. Em termos de perdas na produção, mais da metade dos produtores estimou índices na faixa de $10 \%$ a $25 \%$, sendo que $15 \%$ dos produtores estimaram índices de perdas em torno de $50 \%$, sendo as causas mais citadas: não seguir as recomendações técnicas, doenças, adversidades naturais e qualidade de sementes.

Quanto às operações relacionadas com a preservação dos produtos já colhidos, a embalagem mais utilizada é a de madeira retornável (citada por $52 \%$ dos produtores), seguida da embalagem de plástico retornável (citada por 39\%), sendo que apenas $9 \%$ dos produtores dizem transportar seus produtos em engradados. Em relação ao meio de transporte empregado, mais da metade dos produtores usam veículos utilitários (61\%), enquanto que $27 \%$ utilizam caminhão aberto e apenas $12 \%$ usam caminhão baú sem refrigeração. Nenhum dos produtores faz uso de caminhão baú refrigerado, o que seria ideal para a conservação da qualidade das hortaliças até os pontos de venda. Quando questionados sobre o índice de perdas durante o transporte dos produtos, os produtores foram quase unânimes em afirmar que elas não existem, justificando que o trajeto entre a horta e os pontos de venda é curto e rápido. Os poucos produtores que assumiram existir perda no transporte, afirmaram que ela é mínima (estimada em torno de 5\%). 
Quando perguntados sobre como eles avaliam a qualidade de seus produtos em relação ao que os clientes solicitam, pouco mais de $60 \%$ disseram oferecer produtos em conformidade com o pedido, enquanto que cerca de $35 \%$ afirmaram ofertar produtos com qualidade superior à demandada. Somente um único produtor assumiu que seus produtos estão deixando a desejar em termos de qualidade. Notou-se que, na realidade, eles não possuem dados concretos sobre a opinião dos clientes, tomando-se como referência para a resposta apenas o fato do cliente reclamar ou não dos produtos (se não reclamou significa que a qualidade dos produtos está, pelo menos, dentro do esperado). Ademais, associam melhoria da qualidade com os benefícios financeiros que possam vir a obter com isso: para 55\% deles seria interessante melhorar, desde que recebessem um preço maior. Porém, os demais produtores afirmaram não ser vantajoso trabalhar nesse sentido, já que certamente não receberiam nada além do que recebem.

Quase a metade dos produtores (48\%) assumiu não registrar no dia-a-dia nenhum tipo de informação, usando como argumentos: falta de tempo, falta de costume ou simplesmente por não ver necessidade. Quando fazem anotações, estas se relacionam principalmente ao levantamento de pedidos por cliente (quais produtos, quantidades e preços). Mesmo os que registram demonstraram que não as utilizam para nenhum tipo de análise posterior. Do total, só dois produtores revelaram usá-las para acompanhar a produtividade e os custos mês a mês. Não registrar dados indica uma deficiência em termos gerenciais, que pode ser justifica pelo fato de $85 \%$ dos produtores afirmarem não buscar informações sobre capacitação gerencial.

\section{Considerações finais}

Apesar desses produtores dotarem de um considerável conhecimento tácito do ponto de vista técnico acompanhado da vasta experiência prática, percebe-se uma grande carência de suporte gerencial. Especificamente em relação à gestão da qualidade, com base nas respostas obtidas e naquilo que se observou nas visitas aos estabelecimentos rurais, pode-se concluir que os mesmos se encontram bastante defasados em relação ao mínimo esperado dentro do proposto como referência em termos das dimensões e atividades de gestão da qualidade.

Em relação à primeira dimensão da qualidade apresentada, destaca-se, por parte do conjunto de produtores, a falta de informações precisas sobre necessidades dos clientes, padrões de qualidade dos produtos e legislação em vigor. Isso decorre tanto da ausência de um acompanhamento mais próximo da extensão rural (queixa de grande parte dos produtores), como simplesmente de não irem atrás delas. Muitas vezes essa postura de não buscar informações pode ser justificada pelo fato de ainda não perceberem a importância ou necessidade para a definição de objetivos, sacrificando qualquer tentativa de planejar, um mínimo que seja, o negócio como um todo (planejamento esse que não foi evidenciado).

Apesar de afirmarem realizar controle das atividades, esse fica restrito a um acompanhamento visual (verificar a presença de doenças, o ataque de pragas, ou mesmo em termos da própria qualidade dos insumos adquiridos e dos produtos obtidos, isso quando fazem inspeção). Assim, mesmo que a grande maioria dos produtores afirme ofertar produtos de boa qualidade ou de qualidade superior ao esperado pelos clientes, questiona-se até que ponto isso se confirma na prática. Ou seja, considerando-se algumas informações específicas obtidas em campo - quase a totalidade dos produtores aplica freqüentemente agrotóxicos nas plantas; alguns desses assumem a postura de não seguir o período de carência dos agrotóxicos; mais da metade dos produtores nunca fizeram análise da qualidade da água; alguns produtores embalam os produtos com papéis de jornal oriundos de "ferro-velhos" - questiona-se se a qualidade das hortaliças ofertadas realmente está garantida em termos de segurança do alimento. Do ponto de vista do gerenciamento formal da atividade, os produtores não têm a 
postura de registrar dados no dia-a-dia, muito menos, de convertê-los em informações para análises futuras, que seriam essenciais para formalizar o controle da atividade como um todo.

Ademais, não se evidencia uma preocupação com a melhoria da qualidade, a qual associam à necessidade de altos investimentos e à recompensa financeira pelos clientes, além de quase metade dos produtores não se sentirem motivados para isso por não acreditarem na valorização dos produtos. A falta de postura para melhoria é evidenciada pelos seguintes fatores: ausência de indicadores de desempenho, falta de sistemática para avaliar a satisfação dos clientes, ausência de ações preventivas, não identificação de problemas potenciais que poderiam ser evitados, falta de atuar nas causas dos problemas acabando por permitir eventualmente a recorrência deles. Tudo isso é justificado e agravado, mais uma vez, pela falta de anotar informações relevantes e analisá-las para conhecer os pontos fracos e identificar oportunidades de melhoria.

Por evidenciar a necessidade de organização da produção nesses estabelecimentos justificada pela carência de suporte gerencial, o presente diagnóstico, ao revelar as deficiências e as oportunidades de melhoria, fundamenta o desenvolvimento de um sistema de gestão da qualidade para essas propriedades familiares do município de São Carlos-SP. Um sistema que vise a garantia da qualidade dos alimentos e a melhoria contínua dos processos, vislumbrando benefícios em termos de redução de perdas e de custos e, por conseguinte, de melhores condições ao produtor na árdua batalha diária de comercialização de seus produtos. Nesse sentido, é condição fundamental que tal sistema seja concebido em conjunto com os produtores familiares e instituições afins, de modo a ser o mais simples e objetivo possível, pautado na rotina diária de trabalho, promovendo mudanças gradativas adaptadas à linguagem usual das famílias de produtores bem como à realidade prática específica de seus estabelecimentos rurais.

\section{Referências}

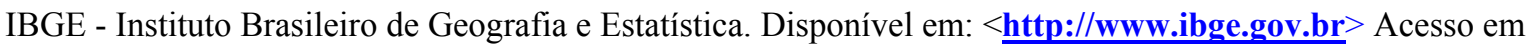
$\operatorname{março/2003.~}$

GOMES, M. S. de O (1996) - Conservação pós-colheita: frutas e hortaliças. Brasília: Embrapa-SPI.

GUANZIROLI, C. et. al. (2001). Agricultura Familiar e Reforma Agrária no Século XXI. Rio de Janeiro: Garamond.

LANA, M. M. et al. (1998) - Manipulação e comercialização de hortaliças. Brasília: Embrapa-SPI/EmbrapaCNPH.

MAKISHIMA, N (1993) - O cultivo de hortaliças. Brasília: Embrapa-SPI/Embrapa-CNPH.

SLACK, N. et al. (1996) - Administração da produção. São Paulo: Atlas.

TOLEDO, J. C. (1997) - Gestão da qualidade na agroindústria. Gestão Agroindustrial. IN: BATALHA, M. O. (org.). Editora Atlas. Vol. 1, p.465-517. 